\title{
A timeline of biological assessments: Our nonspatial continuum
}

\author{
Charles F. Cox ${ }^{1}$, Naotake Akimoto ${ }^{2}$, Shiro Suzuki ${ }^{3}$ and John D. Ruby ${ }^{4}$ \\ ${ }^{1}$ Visiting Professor, Department of Operative Dentistry, School of Dental Medicine, Tsurumi University, 2-1-3, Tsurumi, Tsurumi-ku, Yokohama 230-8501, Japan \\ ${ }^{2}$ Part Time Lecturer, Department of Operative Dentistry, School of Dental Medicine, Tsurumi University, 2-1-3, Tsurumi, Tsurumi-ku, Yokohama 230-8501, Japan \\ ${ }^{3}$ Visiting Professor, Department of Clinical \& Community Science, 1919 7th Ave. S. The University of Alabama at Birmingham, AL 35294, USA \\ ${ }^{4}$ Adjunct Professor, Department of Pediatric Dentistry, School of Dentistry, 1919 7th Ave. S. The University of Alabama at Birmingham, AL 35294, USA
}

\begin{abstract}
Much of our dental history is recognized through oral tradition, which has led to myths \& misconceptions regarding the efficacy of early restorative agents. Dental biomaterial history has tended to report only certain aspects research in a few textbooks that are expensive and not readily available to the larger dental audience. Our purpose is to provide a detailed peer-reviewed document, which provides a chronological account of our in vitro and in vivo biological continuum. This document follows a published historical chronological timeline of biomaterial testing literature beginning with its little known inception in 1779. Many of the early dental restorative agents evolved due to their anodyne capacity to alleviate tooth pain and provide a modest bacteriostatic capacity. Those that were successful were modified as temporary cavity filling agents and evolved to more permanent fillings. Unfortunately, many of the early agents e.g. antimony, arsenic, asbestos, canthrides, formalin, mercury, mustard, phenol to name a few were toxic to the tooth and supporting periodontal tissues as well as failing to support lost tooth structure. The National Institute of Dental Research required biomaterial testing in the late 1940's. Even today, the agency permits many pre-1950 agents via the grandfather clause for commercial inclusion and clinical use, while requiring all new post-1958 agents to pass both in vitro and in vivo testing hurdles. We routinely place restorative agents that infiltrate in graded interphases to interdiffuse into vital enamel, dentine and even cementum by forming a unique biomimetic substrate that mimics the color and opacity of the human tooth. Our biological continuum is still evolving with technologies that will continue to change our clinical future. Our profession has been the global benefactor of dynamic change. Unfortunately, our biomaterials testing status quo is not acceptable as many toxic agents e.g. formalin still remain in our clinics
\end{abstract}

\section{The value of written history}

In the public domain, oral tradition has been handed down through generations that intend to convey practical \& moral accounts of collective wisdoms as to how we should conduct our selves.

Some humans study history from a desire to enhance the understanding of their heritage. Science history stems from a compilation of written accounts by individuals that have become part of our scientific record. In his 1895 inaugural lecture, Lord Acton stated, "science is deposited like the grains of gold in the sand of a river; and the knowledge of the past, the record of truths revealed by experience, is eminently practical, as an instrument of action and a power that goes to making the future" [1].

Euclid's Elements were written circa 300 BC while he lived in Alexandria Egypt-consisting of 13-books-described as the most influential textbook ever written by one individual. It proved instrumental in the development of scientific thought, logic \& methodology_one of the first mathematical works to be printed on a press, only surpassed by the Bible in printed editions [2] Abraham Lincoln kept a copy of Euclid's Elements in his saddlebag \& studied it by lamplight. "You never can make a lawyer if you do not understand what demonstrate means. . .I left Springfield, went home to my father's house, and stayed there till I could give any proposition in the six books of Euclid at sight" [3].

\section{Following the biological timeline of dental material testing}

When did biological testing of dental products \& their components become a concern \& part of the scientific record? What was the $1^{\text {st }}$ U.S. agency to establish biological testing? When did it originate? Is each chemical in the assemblage of our professional \& OTC dental products biologically acceptable? If not, why do some toxic agents still remain in the composition of certain of today's dental products? Which biological test standards came first-in vitro (bench-top) or in vivo (animal)? Now that we have your attention, we'll attempt to answer these questions in the following text.

The origins the National Institutes of Health (NIH) \& the National Institutes of Dental Research (NIDR) are traced to the US Marine Hospital Service (MHS) of 1779 that provided medical care for merchant seamen. By 1880, European scientists had established that person-toperson contact of bacteria caused cholera \& that mosquito borne blood

Correspondence to: Charles F. Cox, Visiting Professor, Department of Operative Dentistry, School of Dental Medicine, Tsurumi University, 2-1-3, Tsurumi, Tsurumi-ku, Yokohama 230-8501, Japan, Tel: 1 (810) 275-8361; Fax: 1 (810) 6364201; E-mail: cfcoxctwos@gmail.com

Key words: bacteriometic, biocompatibility, in vitro, in vivo, pulp, seal

Received: March 20, 2016; Accepted: April 15, 2016; Published: April 20, 2016 
bites transmitted malaria [4,5]. As a result of these \& other findings, the MHS was charged with expanded clinical duties at Ellis Island to inspect immigrants for infectious diseases. Dr. Joseph Kinyoun-a MHS physician/microbiologist at the MHS Hygiene Laboratory Staten Island-was able to identify bacteria in sick immigrants for diagnosis of infectious diseases (e.g. cholera) \& to quarantine them to prevent the spread of disease amongst the general population [6].

Perhaps the first dental restorative agent to arouse professional scrutiny was the introduction of dental amalgam during the American colonial era. Circa 1834, Edward \& Moses Crawcour traveled from Europe to tour the colonies to introduce their quicksilver paste to colonial dentists. With no formal dental training, they rapidly became recognized as frauds with no ethical scruples. Lacking clinical cavity preparation \& restorative standards, many clinicians experienced poor amalgam outcomes.

Without amalgam standards, clinicians would file tiny flakes of silver from the edges of coins \& triturate them with mercury in a mortar \& pestle for a few moments. Some placed the mix in a cloth pad to squeeze out excess mercury \& a few even manipulated the mix in their palm \& thumb to determine its plasticity before plugging it into the tooth. In those decades-before G.V. Black-mercury became an easy blame for failed amalgam restorations.

Many charlatans \& untrained colonial clinicians attempted a crude effort to remove cavity debris \& to plug the defect with amalgam, without paying attention to periodontal health, tooth contact \& anatomical contour. A few weeks post insertion often resulted in gingival \& pulp pathology. An outcome observation of that era showed the damaging effect of amalgam was improper clinical insertion [7]. It wasn't until the late 1800's when G.V. Black gave his independent research on principles of cavity preparation \& amalgam composition to the dental profession [8]. He made no personal patent claims for his research. His time, talent $\&$ financial research support was entirely his own-there was no government funded dental research of those decades.

Through the late 1500 's to the mid-1800's there were several different theories regarding the cause of human caries. For a comprehensive review of caries literature, we refer the reader to the 2010 article by Ruby [9]. By the early 1900's, only a few clinical colleagues treated caries as a bacterial disease or thought about caries prevention. Until then, most clinicians of the young profession were mainly concerned with the restoration of carious lesions.

In 1888 , Dr. Kuehns was one of the $1^{\text {st }}$ to report on correlation of fluoride \& mottled enamel to reduced caries. He observed a rural family with mottled brown-spot enamel, which he attributed to excess fluoride intake [10] Research by Eager \& McKay also associated fluoride to reduced caries $[11,12]$.

\section{Authorities search for answers}

Thousands of young men were rejected from military service during WW-II due to extremely poor oral \& dental health. The armed forces health service branches convincingly lobbied the US Congress to create an agency to study \& provide oral health standards for incoming military recruits. On June $24^{\text {th }} 1948$, President Truman signed legislation for the formation of the NIDR as the $3^{\text {rd }}$ arm of the $\mathrm{NIH}$. Its formation was a consequence of lobbying efforts of the armed forces to learn why so many young men were rejected from service. The NIDR was charged to identify the cause of caries \& pyorrhea \& to seek preventive agents $\&$ treatments that would benefit society at large [13].
In 1958 President Eisenhower signed legislation to fund construction of the NIDR facilities in Bethesda MD that became reality in the 1960's [14]. Research directives were immediately implemented, which enabled Dr. Dean to establish water fluoridation studies in various US communities \& to identify it's effects on prevention of tooth decay [15].

\section{Establishing biocompatibility testing standards}

Dr. George Charpy, a noted French chemical engineer of the late 1800 's, wrote that "development \& analysis of materials testing of any future agency should establish any new material as judged only by performance tests. . .give a meticulous and precise description of all tests; avoid all vagueness that permits or necessitates any arbitrary decisions on the part of the personnel doing the testing; specify the relation between the precision of the testing and the precision required in the results of the tests; and state how the data are to be recorded" [16].

To solve the testing conundrum, the NIDR \& Food \& Drug Association (FDA) agencies were required to identify biological compatibility \& safety of pre-1948 as well as new dental restorative materials. To provide a reasonable answer to the safety issue of toxicity, the NIDR \& FDA committees created a "grandfather clause" that granted acceptable use of all pre-1948 dental restoratives that had been in clinical use since the emergence of US dentistry in the late-1700's \& for new U. S. Class I \& Class II materials \& devices.

In the 1950's, there were no operational biocompatibility research guidelines that existed. The question was: what should be the NIDR recommended standards to use on all new dental agents destined for clinical use? Since there were hundreds of historical dental agents, an almost impossible research task existed to rapidly test the biocompatibility of agents that had been around for 150-years-let alone new agents. If In their group decision, the committee's supposition was, that if the pre-1948 agents had been in clinical use \& clinically acceptable, then they must be biologically satisfactory. Consequently, 1948 was the starting point for biocompatibility testing-any agent developed after 1948 would be subject to new testing standards [17]. And if the mechanical properties of new agents were equal to or better than pre-1948 products, they were then submitted to an independent research laboratory for biological testing.

Many of today's clinical restoratives \& devices have successfully passed the $1^{\text {st }}$ test gate-an in vitro cell culture biocompatibility test against positive \& negative controls. The $2^{\text {nd }}$ test gate for the restorative agent is submitted for in vivo biological evaluation by implanting the agent into the soft tissues of small animals (rat, mouse, rabbit). If successful, the agent is next submitted to a $3^{\text {rd }}$ in vivo usage test into facial cavities of non-human primate teeth at 3-time periods to evaluate the histologic response in non-exposed \& exposed Class- $\mathrm{V}$-cavities. Following compliance through the 3-test gates, it is then submitted for the human clinical testing under defined conditions [18].

\section{Material sensitivity causing irritation}

Several commercial dental technic laboratories may use nickelsensitizing metals to fabricate restoratives, which have a lower cost than noble metals. In addition, some company's produce agents which contains aldehydes, phenols, ketones, which are known to be toxic when evaluated by current FDA \& International Organization for Standardization (ISO) in vitro \& in vivo biocompatibility tests.

To informed clinicians \& patients, the question remains, can FDA, ISO, NIH, NIDCR \& the ADA continue to permit sales \& use 
of these agents in humans? It may be explained: most international dental groups retain their own grandfather clause or they rely on the US 510-K document that permits use of toxic aldehydes, formocresol or phenols-since they are certified as germicidal-even though they dehydrate, burn \& also denature vital tissues if not properly applied. Ironically, some of today's dental restoratives contain these \& other known carcinogens, even though they were grandfathered before the FDA had developed biological testing standards.

Certain crowns \& bridges are fabricated with non-noble nickel or beryllium, which are known to sensitize vital tissues, causing redness \& swelling that often leads to chronic itching \& a skin rash in the mouth, face, arms, legs \& torso of humans. If severe oral sensitization persists, the main clinical recourse is to remove the offending restoration.

As discussed above, pre-1948 NIDR grandfathered agents, are not held accountable by today's biocompatibility standards, even though some would fail the initial in vitro tests if tested today. Biocompatibility data show that cell sensitivity, irritation \& toxicity may lead to necrosis when placed on vital tissues.

Fortunately for today's patients, most countries follow international harmonized biocompatibility standards for clinical use. For patient safeguard, new products must $1^{\text {st }}$ pass material function \& suitability tests-followed by in vitro \& in vivo tests \& if they harmonize with International tests-they may proceed to the dental marketplace. However, since a new product contains grandfathered glutaraldehyde or phenol agents, they are not held accountable to the same long-term functional \& biocompatible standards as a new chemistry, so they may proceed to the commercial marketplace as some component was grandfathered before biological tests were required.

Caveat emptor-buyer beware. When a new restorative agent is brought to your clinical attention-you should request from the company, all Material Safety Data Sheets (MSDS) data, which supports the new agents long-term clinical safety for patient use-otherwise you may inadvertently place a new restorative agent with minimal clinical benefit that may cause irritation $\&$ lead to possible failure.

\section{Which biological tests came first? In vitro or in vivo}

Origins of the scientific method may be traced to Anton von Leeuwenhoek, who gained notoriety for developing the microscope in the late 1600 's. Without a formal doctoral thesis, he was perhaps the $1^{\text {st }}$ to use common sense methodology, wherein he defined questioning steps that led to the development of his own scientific methodologyin part the basis of today's research methodology [19].

Any colleague who plans a research project should understand the scientific method. It involves development of some personal interest, after which they formulate a working hypothesis. They should next formulate a NULL hypothesis-a non-relationship between 2-measurable ideas or observations. Next, they should collect relevant literature to understand what previous research has been carried outto prevent reinvention of the wheel.

Before computers, research colleagues often spent days in medical \& dental libraries to collect notes on methodologies \& read publications related to their field of interest. This process was often the most challenging in the development of any study. Today, literature is easily accumulated from the www using only a few key words, with the Information easily gathered in just a few minutes.

In 1926, Dr. Souder at the US National Bureau of Standards (NBS) framed specifications for dental amalgam using previous published research by Dr. G.V. Black [20]. The ADA-established in 1859 \& reorganized in 1922-adopted laboratory \& clinical testing as their controlled research discipline in 1930, using Dr. Charpy's advice to establish the Council of Dental Therapeutics to oversee the evaluation of dental products. Since then, other groups have attempted to provide worldwide harmonization of testing \& certification standards. Over 100 -countries are members of the 1952 ISO formulary that promotes harmonization of dental materials biocompatibility test standards. It is ironic that even though the US has membership in the ISO, it still holds fast to their FDA regulations, which remain independent of ISO guidelines-at the same time both standards reach similar end results [21].

In 1948, the Federation Dentaire Internationale (FDI est.1900), The American Association of Dental Schools (AADS est. 1923), The International Association for Dental Research (IADR est. 1920), The Dental Manufacturers of America (DMA est. 1932) and the Food \& Drug Administration (FDA est. 1968) each contributing to the development of dental material specifications.

And so, when did dental material biocompatibility testing begin? Dental literature suggests that biocompatibility testing was fostered, by growing interest in poor root canal treatment outcomes. In 1901, Dr. Hunter of London UK spoke at McGill University in Canada, where he publically condemned root canal treatment for causing dental infection, septic gastritis \& many other systemic infections [22]. His concept was accelerated in 1918 by Dr. Billings who promoted the concept of focal infection \& necrosis as being caused by septic root canal treatment. Billings claimed root canal treatment was responsible for causing heart disease, arthritis, anemia \& most systemic diseases. His recommendation was simply a call for complete extraction of all teeth-as a general cure. That practice provided an economical windfall for many dentists by complete extraction of teeth of young adults, followed by the fabrication of dentures to remedy the issue of decayed teeth [23]. From discussions with aged edentulous adults who lived during the focal infection era, we learned that many patients had their teeth extracted in a "preventive attempt" to avoid systemic infections. In reality, their treatment often left them with poor fitting dentures that were generally no better than the possibility of decayed teeth \& periodontal disease, in which they were told they would suffer.

\section{Root canal treatment finally gains respectability to ad- vance in vivo testing}

Drs. Hunter \& Billings damned vital pulp capping that led to root canal treatment \& repeated clinical visits for additional treatment \& ultimately extraction resulted in "bad press" for clinicians attempted such procedures. In 1936 Drs. Fish \& MacLean, published clinical data, demonstrating that sterile root canal procedures promoted a new era of respectability by clinicians \& the general population [24].

Additional research by Dr. Bernhard Gottlieb of the University of Vienna reported on histological biocompatibility reactions in animals, which supported sterile clinical procedures [25]. In 1931, Drs. Rickert \& Dixon from the US presented their study "Implantation of a hollow polyethylene tube" at the $8^{\text {th }}$ Int. Paris Dent Congress. They filled tubes with restorative agents \& placed them in the connective tissues of various laboratory animals \& evaluated the histological effects at specific time periods [26]. Their report inspired hundreds of research studies on dental material biocompatibility by Drs. Grossman, Ingle, Hyakusoku, Nicholls, Rowe, Torneck, Seltzer \& many others [27-34].

Chapter-13 of the 1975 ADA publication Guide to Dental 
Materials and Devices committee-chaired by Dr. Stanley-provided 225-references that critically reviewed Endodontic Instruments, Devices and Materials [35]. They reported the "real strength of in vivo studies" provided a dynamic physiological component of a vital milieu of arterial \& venous circulation, neurotrophic influences, hormones, enzymes, connective \& inflammatory cell modulation, which yet today-remains outside in vitro capabilities.

\section{In vitro biocompatibility research as an alternative analysis}

A number of in vitro technologies were proposed in the early 1900's to evaluate the use of vital cells in an artificial media. However, in vitro tests were restricted as to what could be placed into the medium to control such variables as serum composition, incubation temperature, ideal $\mathrm{pH} \&$ agitation.

The 1959 dental literature records that Dr. Kawahara \& colleagues from Osaka University published the first in vitro biocompatibility tests on a silver-tin amalgam [36]. Other parallel studies by Drs. Maizumi \& Sauerwein, Keresztesi \& Kellner, Leirskar \& Helgeland \& Spångberg reported on the in vitro biocompatibility of dental materials by tissue culture [37-40].

Comparing dated timelines of dental materials biocompatibility research-in vivo studies were first reported. However, in vitro research has since increased in its sophistication \& model types. Today, many cell lines have been developed for studying dental \& medical materials \& devices. Differing opinions discuss the importance of using primary cell lines from mice, rats, rabbits or humans. Should we use primary organ cultures, or primary human adult diploid cells with 46-chromosomes, or should we use cell lines with an unusual number of chromosomes?

Silicate cement was the $1^{\text {st }}$ restorative agent to promote in vivo biocompatibility testing. A 1936 in vivo study by Dr. Manley was first to report biocompatibility research on silicate, 19-years before Dr. Kawahara published his in vitro research [41].

Tooth-colored silicate was $1^{\text {st }}$ used by Thomas Fletcher in 1873 England [42]. However, it never became popular until modified with fluoride as Ascher's Artificial Enamel by Dr. Schoenbeck of Germany in 1907 [43]. In 1925, several commercial cements were available to the US dental market; zinc oxide powder used eugenol as its mixing solvent became a popular zinc oxide eugenol ( $\mathrm{ZnOE})$ pulp protectant against tooth sensitivity. Silicate \& zinc phosphate cements both used phosphoric acid $\left(\mathrm{H}_{3} \mathrm{PO}_{4}\right)$ as the liquid solvent. After placement-due to a long gel-set phase-the silicate surface was covered with petrolatum to provide an air-inhibited layer as it passed thru a 24-hour reaction. This allowed the patient to leave the clinic \& return after several days for final finishing \& polishing [44]. But many patients avoided this return trip, due to added chair time \& expense. Unfinished silicates easily stained with tea, coffee, red wine, foods \& the cavity margins soon became ditched leaving exposed enamel for easy microleakage into the restorative interface. Non-fluoridated silicate became demonized due the $\mathrm{H}_{3} \mathrm{PO}_{4}$ etching of the smear layer \& tubule plugs-during the 24hour gel-set stage-allowing fluid flow along the restoration interface \& into the open dentine tubules-causing dentine hypersensitivity \& patient tooth pain, especially when drinking iced beverages or eating icecream [45]. Non-fluoridated silicates permitted bacterial microleakage, leading to recurrent caries that resulted in pulp inflammation \& necrosis. Whereas, fluoridated silicates \& glass ionomers are known to recharge with fluoride from toothpaste \& other agents to prevent recurrent caries [46]. Clinical data show that 50-year old fluro-silicate restorations show no recurrent caries. Clinicians have been reported to state at meetings, "If it isn't broken, leave it alone", That clinical observation speaks volumes for the preventive effect of fluoride-long before todays "new found" clinical outcome analysis-the supposed new research mantra-then again, long-practicing clinicians have said for decades that their clinical outcomes have always been their true reality. Is the issue of clinical outcome analysis really new?

\section{Myths or misconception? Do acids kill the vital dental pulp?}

In 1936 Dr. Manley was first to publish in vivo pulp biocompatibility data. He placed a number of class $\mathrm{V}$ dental restorative materials in dog teeth, reporting that vital pulps restored with silicate, copperoxyphosphate \& amalgam became inflamed \& necrotic due to the phosphoric acid solvent. Conversely, he postulated that cavities restored with $\mathrm{ZnOE}$ were "pulp protected" as no inflammation was observed [47]. Today's research has shown that eugenol is both sedative \& germicidal. Manley's 1936 article was the $1^{\text {st }}$ publication to condemn cements with $\mathrm{H}_{3} \mathrm{PO}_{4}$ by causing pulp inflammation. His 1943 publication on human teeth planned for orthodontic extraction, showed severe pulp pathology, which he reasoned was due to acid cementsthose same patients reported cold hypersensitivity. Even Drs. Gurley \& van Huysen supported-quite incorrectly-that Manley's concept of toxicity was due to phosphoric acid. Today, Manleys acid theory of pulp death is incorrect [48]. We find it remarkable that in 1927, Dr. Crowell-a chemist at the U.S. National Bureau of Standardsspeculated that bacteria were responsible to cause pulp inflammation \& not $\mathrm{H}_{3} \mathrm{PO}_{4}$ acid [49]. In 1961, Dr. Roydhouse stated " $\mathrm{pH}$ is a measure of hydrogen-ion concentration in solutions, it is not suitable for describing some property of solids. Presence of a large buffering agent such as the calcium hydroxyapatite of enamel \& dentine \& the addition of an acid or alkali alters the $\mathrm{pH}$ but little, until the buffer is used up. . .since dentine \& enamel are great reservoirs of a high $\mathrm{pH}$ alkaline buffer, their high $\mathrm{pH}$ will rapidly neutralize most acids, above all, a small drop of $\mathrm{H}_{3} \mathrm{PO}_{4}$, before reaching the pulp...The [alkaline] nature of tooth material makes it doubtful that acid could be the sole cause of pulp degeneration beneath unlined silicate restorations" [50].

Meticulous in vivo human tooth pulp studies by Dr. Brännström demonstrated-beyond any doubt—that pulp inflammation was due to bacterial infection \& not from acid toxicity [51]. The Achilles heel of Dr. Manley's study was-he failed to apply controlled bacterial stains to micro-slides of dentine \& inflamed pulps. He speculated that the rubber dam provided a complete bacterial barrier during treatment. He was totally unaware that microleakage of bacteria through the restorative interface post placement caused pulp inflammation. Today, well-defined pulp biology usage tests are required by ISO to include properly controlled bacterial stains as part of any in vivo test [52].

\section{In vivo biocompatibility test models}

Implantation tests vary with the animal model. Any dental agent is mixed per directions, immediately placed into sterile polyethylene tubes \& implanted into connective tissues of mice, rats or rabbits for prescribed times. Tests generally used control agents, such as polyethylene tubes filled with sterile bone wax or $\mathrm{ZnOE}$ agents as per Dr. Torneck's model [53]. Reports were mixed as some publications reported that silicate alone caused slight tissue reactions while others reported more severe tissue responses. Unfortunately, results from different studies were often downplayed or excluded due to obscurities 
in distinguishing tissue damage from the placement surgery when compared to the various tested agents. Some modifications of surgical tissue implantation have been suggested \& actually implemented, but there still remain a number of strong opinions as to just why any one specific test is supposedly more reliable than another-it is difficult to standardize subjective or biased opinions of individual researchers.

Some researchers used gingival tissue responses in an attempt to evaluate any dental material that lies in direct contact to the gingival-agent interface. When measuring the gingival response to amalgam, silicate or resin restorations, their histological responses are often judged as similar. As a consequence, it has been suggested that mechanical surface defects-smoothness, roughness \& plaque biofilm-are more responsible for a severe gingival response than the biocompatibility of the dental agent itself.

Hypersensitivity patch tests were used by Bergman in 1977, reporting a number of observations in patients demonstrating severe gingival reactions, ranging from slight erythema to strong vesiculation due to cobalt, nickel \& cadmium containing alloys that are used in some pediatric crowns \& solders [54]. Many patients today are increasingly becoming subject to nickel hypersensitivity-even more importanthypersensitivity is a greater concern to laboratory technicians \& office personnel who are in daily contact with nickel, beryllium \& other fine particles. Those patients with crowns containing high beryllium content often report severe hemorrhagic gingiva when in direct contact with the final restoration. The only clinical recourse is to remove the entire restoration \& replace it with a non-irritating adhesive composite or ceramic restoration. It is important that clinicians, office personnel, technicians \& patients be made aware of the metal composition of the final restoration content. Clinicians should validate that each patient does not have any in vivo hypersensitivity to known metal irritants such as nickel, beryllium or copper.

\section{Evolution of international in vivo testing specifications}

In the late 1800's, the US National Dental Association Research Institute had focused its effort to support the evaluation of biological \& preventive aspects of new dental materials, but their financial support for biological research testing was limited, especially when compared to the large volumes of new data that were being produced on the physical \& mechanical aspects of amalgam. After lengthy efforts to publish their amalgam data Drs. Souder \& Peters-finally could realize that peer review colleagues accepted their data, which was published in the 1920 Dental Cosmos [55].

In the early 1900's, many dental agents were natural resins, waxes, essential oils, alginates \& zinc cements used for dentures. In the last half of the 1900's, dental procedures moved from extractions \& dentures towards operative procedures with enamel \& dentine interdiffusion of interphase hybridization with adhesive polymers. In a dynamic sense, progress of harmonization testing remains increasingly strategic to developing new standards for biocompatibility testing of restorative products.

In the early 1900's, most researchers were content to use their own in vivo biocompatibility test models-consequently, most in vivo studies were of individual design \& not well suited for harmonization, since their test bore little correlation to other in vivo studies. As harmonization progressed, new dental agents were placed in the teeth of several animals of a similar age, tooth-type, maxillary \& mandibular quadrants \& compared against 2-controls. In early in vivo pulp biology studies, silicate \& $\mathrm{ZnOE}$ were selected to serve as positive \& negative biological controls with 3-specific placement intervals (short, intermediate \& long-term) with new agent histology compared to at least 2-unknown double-blind controls.

Early peer reviewed pulp publications established standards, which most organizations now follow. In vivo primate placement in class- $\mathrm{V}$ cavities became the accepted $3^{\text {rd }}$ biocompatibility test-gate with the particular agents placed under the same clinical conditions as in humans [56-65].

By 1978, the ADA published the $8^{\text {th }}$ edition of Guidelines to Dental Materials and Devices "Recommended Standard Practices for the Biological Evaluation of Dental Materials", which were intended guidelines for the testing of new products [65]. With the great rush of new adhesive restorative systems-it should be noted that phenol, acetone, ethyl alcohol, formocresol \& glutaraldehyde are toxic \& mutagenic in various concentrations $\&$ in time of direct contact. They had been grandfathered in the 1948 mandate. If glutaraldehyde were brought to the dental marketplace as a new dental agent, it would fail to pass the $1^{\text {st }}$ in vitro biocompatibility test-gate. Thus glutaraldehyde would not be approved to advance to the $2^{\text {nd }}$ in vivo or $3^{\text {rd }}$ primate usage test-gate $\&$ to the $4^{\text {th }}$ human clinical test path.

In 1978, the FDI adopted Technical Commission Report ${ }^{*} 204$ "Recommended Standard Practices for Biological Evaluation of Dental Materials" compiled by the FDI working group. It contained hundreds of pages of laboratory tests proscribing the biological evaluation of dental materials. That document was recognized as the $1^{\text {st }}$ modest attempt to establish uniform testing procedures-adopted "with the intention that any particular dental material should not be subjected to all suggested tests. . .the manufacturer could select the most important test they felt appropriate". The reader is referred to recent ADA/FDI/ ISO documents for the most current revisions that are found on the web [66].

In 1997, ISO published their $2^{\text {nd }}$ edition of: 10993-1 Biological Evaluation of Medical Devices, composed of 16-detailed sections [67]. It is a revised document, by which all member bodies-composed of manufacturers, academics, researchers-had met over several years, in an attempt to harmonize the many different standards from various countries such as Germany, England, New Zealand, Australia, Japan, US \& many other countries. That final document is a detailed compilation of hundreds of pages that cover general as well as specific detailed biocompatibility tests that must be followed, before the agent passes to the next challenge. Paradoxically, even though the U.S. is an active member of the ISO Harmonization Group process \& has even hosted several ISO meetings, the U.S. still remains independent in many of the ISO harmonizing tests.

When any dental product is found to comply with final official ADA specifications, then the commercial name may be placed on the List of Certified Dental Materials \& Devices. Following such an announcement, the manufacturer may then use the seal in their promotional materials \& labeling that the product complies with official certification \& to allow them to display the ADA Seal of Certification on their product.

From the 1950's until now, researchers have added their own personal modifications to different in vitro tests. One of the earliest in vitro tests was the hanging drop method, which could be carried out quite economically on glass slides. But, without coordinating harmonization, some countries began to promote their own in vitro test, each of which had its own supposed particular advantage \& 
possible disadvantage. The challenge during the 1960's was that not any one international group had taken a firm leadership role, as many countries were developing \& promoting their own biological testing standards.

\section{Are we there yet? Has biocompatibility harmonization been achieved?}

IADR Pulp Biology Group (PBG) records show that Dr. William R. Cotton was the driving force to standardize Biological Testing Standards. Dr. Cotton was Chairman of the U.S. Naval Medical Research Institute Dental Sciences Department in Bethesda MD-his foresight \& leadership at the 1975 IADR meeting in London culminated in formalization of the IADR PBG. As the PBG Charter President, Dr. Cotton immediately brought together a diverse group of dental researchers-Drs. Kawahara from Japan; Tronstad from Sweden; Avery, Langeland \& Spångberg from U.S.; Klötzer from Germany; \& other world colleagues. In just 2-years, Dr. Wm. Cotton organized the $1^{\text {st }}$ international PBG Symposium on Methodology \& Criteria in the Evaluation of Biologic Effects of Dental Materials; held at the 1977 IADR meeting in Copenhagen Denmark [68]. At that International Symposium, Dr. Cotton challenged the PBG membership to read the Presidents Science advisory committee: B-4 Recommendation [69]. It stated that "full but critical use should be made of safety and efficacy data from other countries when the data tended to support, as well as when they tend to negate a conclusion of either safety-in-use or efficacy". Dr. Cottons closing comments were: "We must not be frozen into standard protocols, likewise our minds must not be frozen to old \& outdated ideas on testing. Adaptability \& change are paramount." IADR-PBG records detail the strong leadership of Dr. Cotton [70]. However, it is ironic that the IADR PBG Group-the brainchild of Dr. Cotton-has never recognized Dr. Cotton with their annual Pulp Biology Award for his many accomplishments that paved the road for ISO standardization guidelines-perhaps he will receive that recognition someday a largely overdue honor that is more than justly deserved.

\section{The biocompatibility testing stage was finally estab- lished}

Dr. Kaare Langeland-a charter member \& driving force of the young PBG-stated "Until passage of the Medical Device Bill by the U.S. Congress in 1976 testing of biologic effects of dental materials has not been a serious effort". Dr. Langeland noted "the U.S. ADA \& the National Bureau of Standards (NBS) had directed most of its resources on physical properties no similar support has existed in the biologic field". Dr. Langeland pointed out that "the relevant NIH section was pure and free of any speaker on the biologic properties of the involved materials the great majority $90 \%$ were old known investigators of physical properties". Dr. Langland's final comments remain prophetic even today when he stated "biological testing is extremely expensive, particularly the full scale usage tests the purpose of my presentation is to lead into a discussion of possible correlation present available screening tests \& usage tests for local toxicity". Today, almost 4-decades after Dr. K. Langland's challenge, his remarks ring clear-have we finally settled the harmonization concerns of biocompatibility testing?

\section{The 1977 pulp biology symposium: materials screening standards}

Dr. Leif Tronstad reported that a number of in vitro tissue culture tests to assess material cytotoxicity had been developed by various colleagues in just one decade. Even though some meaningful in vitro data had been obtained, many tests were time-consuming, expensive \& needed elaborate equipment that tended to be difficult for many laboratories to acquire. By 1969, Dr. L. Spångberg had developed a radiolabelled chromium release method with the supposed advantage by which various stages of mix of any agent could be tested [71]. However due to strict governmental regulations, many laboratories remain inadequately equipped for proper handling \& their disposal of radioactive agents. In 1977 Dr. J. Autian described an agar overlay tissue culture test, which depended on the capacity of the test material to diffuse through an in vitro agar medium to supposedly exert its toxic influence in the system [72]. In 1979, Dr. L Tronstad proposed improvements to the in vitro Millipore filter test method that was designed to assess \& rank the toxicity of the tested material against controls [73].

Following PBG committee meetings that had evaluated the development of different tests-they suggested "in vitro tests of meaning" should depend on direct cell-to-material contact with an intervening agent. The PBG working group settled upon a simple Millipore filter test method with minimal testing devices \& equipment \& more important with cell-to-material contact having been established with Millipore filters. An elaborate human epithelial (HeLa) cell test was established as a monolayer on Millipore filter discs of 0.45 to $8 \mu \mathrm{m}$ dimensions, incubated \& immediately placed on an agar plate with the filter disc on top. The dental material to be tested was mixed per directions \& immediately placed into a sterile glass ring. After setting had occurred, it was placed on the filter-agar overlay \& incubated for 2-hours, after which the glass test rings with attached cells were further incubated for several hours in oxidative enzyme systems to assess for cell damage to the monolayer cells using specific stains. Zones of enzyme inhibition for each tested agent were observed to measure the cell inhibition toxicity of the agent \& compared to the suggested positive \& negative control agents.

\section{Current in vitro cytotoxicity biocompatibility tests: 2009}

Since 1999, the ISO working committees (BS EN ISO-10993-5) for the Biological Evaluation of Medical Devices have met each year \& reviewed data to create realistic harmonization codes for the testing of any new dental device or material \& to update the 10993-5:1999 document. That revision was published in July 2009-a hardcopy is available to ISO members for $£ 85.00 \& £ 170.00$ for non-members that consists of 20-parts under the general title of Biological evaluation of medical devices-Part-5 deals specifically to any Tests for in vitro cytotoxicity. Since Professor Kawahara's 1955 publication, many models have been proposed, the committee has noted that due to the general applicability of in vitro cytotoxicity tests \& their widespread use in evaluating a rather large range of materials \& devices, the real purpose of the ISO-10993-5 is only to provide a roadmap or scheme for in vitro testing, which requires decisions to be made in a series of steps-rather than to specify any one particular test. In this way, the selection process should lead the company \& testing organization to the most appropriate test for their new device or agent.

The committee identified 3-tests: an extract test; a direct contact test $\&$ an indirect contact test. The choice of any one or more of these 3-depends upon the nature of the sample that will be evaluated, the potential site of material or device placement in the organism \& the nature of the use of the same. The intention of the ISO 109993-5:2009 is to leave open the choice of the test type, allowing the strategy to make available a battery of tests, which reflects the approach of many 
organizations or groups that suggest or require in vitro tests. Once decided, the details of material or device preparation; the preparation of the cultured cells \& the manner in which the cells are exposed to the samples or extracts are then determined. At the end of the exposure test, the evaluation of the presence \& extent of the in vitro cytotoxic effect is determined.

The 10993-5:2009 committee redefined in vitro cytotoxicity test methods, so endpoints could be grouped into the following categories of testing evaluation. 1) Morphological assessment of cell damage. 2) Measurements of cell damage. 3) Measurements of cell growth. 4) Measurements of specific aspects of cellular metabolism. An investigator must realize that there are several means of producing results in each of these 4-categories \& so they must be aware how the tests fall into certain categories as well as to employ both positive \& negative agents for test controls. In addition, the investigators should also compare their material/device to similar products. For guidelines of quantitative test protocols, the ISO-10993-5:2009 committee has also provided 24-annexes for guidance of interpretation of the results [74].

Even though the ISO committees have been diligent to reconcile biocompatibility-testing programs since the 1970's, there is still not any single comprehensive in vitro test that mimics the actual in vivo conditions found in the mouth. Dr. Brännström demonstratedthe elephant in the room-the dynamic dimension of bacterial microleakage plays the most prominent in vivo role that is difficult to mimic in vitro [75]. Consequently, an elusive correlation remains between in vitro \& in vivo tests \& the search to more closely simulate in vivo circumstances are still advocated. As Dr. Cotton stated in 1977 "Adaptability \& change are paramount".

\section{Is there a definitive in vitro biocompatibility test model?}

If you have followed our chronological timeline of in vitro versus in vivo testing, you may realize that no simple or easily reproducible answer has yet presented itself-a proper scientific answer for biocompatibility testing is simply not easily reported by a simple yes or no response.

A number of in vivo animal \& human usage studies (Kakahashi, Brännström, Bergenholtz \& Cox) have demonstrated-beyond a doubt-that certain bacteria \& their toxins can easily infiltrate into enamel lamella \& restorative channels \& rapidly penetrate down to the enamel-dentine-junction (EDJ) [76-82]. From this point, the bacteria \& toxins can easily spread along the EDJ interface, where they penetrate into $\&$ through the dentine tubule complex. From this point, they may initiate a low-grade irritating response to the primary odontoblasts, in which the primary odontoblasts may respond by depositing a thin layer of reactionary dentine. However, if the insult persists as a chronic effect, the primary odontoblasts often die-whereby certain undifferentiated cells of the pulp proliferate to the dentine interface to form new odontoblastoid (like) cells, which rapidly proceed to deposit a new layer of reparative dentine directly adjacent to the bulk of the tooth's secondary dentine. However, if the bacterial insult is persistent, it may easily cause pulp inflammation \& regional pulp necrosis occurs (Van Hassell) [83]. Such dynamic factors of microleakage \& bacteria are extremely difficult to control \& even more so, bacterial factors are difficult-if not impossible-to simulate in typical in vitro bench top studies - the ISO committee is still waiting for such well controlled in vitro tests to be repeated by "certified research laboratories".

Reflect on the following research data to assist your own interpretation: 1) In vivo research data were first published in 1936 by Dr. Manley-implicating the $\mathrm{H}_{3} \mathrm{PO}_{4}$ component of silicate cement as the toxic factor to vital canine dental pulps. 2) It wasn't until 1955 that Dr. Kawahara's in vitro tissue culture tests were published on silver-tin dental amalgam. 3) In 1968, Dr. Brännström demonstrated in controlled human studies-that silicate cement was non-toxic to vital pulp cells-bacteria were the causative agents for caries \& pulp necrosis through microleakage along the restorative interface. 4) In 1977-after several years of personal travail with pulp biology research colleagues-Dr. William Cotton organized the $1^{\text {st }}$ IADR PBG Symposium in Copenhagen, which strongly advocated for the creation of harmonized biocompatibility standards-Dr. Cotton was $1^{\text {st }}$ to move towards harmonization of biocompatibility testing. 5) After years of meetings, the ISO committee published their $1^{\text {st }}$ Book of Harmonized Biocompatibility testing standards in 1999. 6) In 2009, the ISO committee published revised testing standards that serve as suggested standards, which may be chosen for evaluation by the "developing group" for biocompatibility validation.

\section{Are toxic agents present in today's restorative agents?}

Yes. The facts remain-there are still certain toxic agents, which are minor \& major components of restorative dental systems that range from irritating-to-mutagenic-to-carcinogenic \& toxic when they contact vital tissues. For instance, research publications report that the toxic chemistry of certain polymers, aldehydes, formocresol, hydroxy ethyl methacrylate \& bis-phenyl-A are known irritants, which range from mild-to-toxic with International test standards [84-88].

It remains somewhat curious that the infamous grandfather clause-since 1948 - continues to permit many of the known irritational \& toxic agents that are a minor component of "newly developed" dental restoratives. In addition to the various chemicals certain nickel, cadmium, zinc, copper metals are commonly found in many cosmetics, are also known to cause sensitizing reactions in humans. In 1991, Lucas discussed various degrees \& side effects of biodegradation of dental metals [89]. Again, even with the continued ISO acceptance of these grandfathered irritating dental products-many worldwide dental agencies continue to permit their clinical use in humans-even though some are classified as germicidal [90]. Additional studies have documented that high concentrations of alcohols, aldehydes \& acetone may rapidly dehydrate \& denature vital cells, collagen fibers \& other proteins especially when improperly placed by the clinician. Today, the dental marketplace continues to sell restoratives that contain glutaraldehyde, phenol \& lead that are potentially toxic, not only to the patient but also more importantly to those office personnel who work in the clinic environment on a daily basis.

\section{Can researchers have it both ways by choosing their fa- vorite in vitro test?}

Reaching this point in the manuscript, we realize that the ISO-10993-5-2009 committee in vitro tests recommendations are only suggestions. They serve as the first biocompatibility "test gate", especially when a new dental restorative product or device is developed for use in the oral cavity. Once the developing agency has passed their own personally chosen in vitro biocompatibility test-they can then move to the next in vivo biocompatibility-testing gate-again an animal system of their choice. Animal tests involve the surgical placement of the agent into the connective tissues of the tissues of rats or rabbits for certain periods of time along with positive \& negative control agents such as $\mathrm{ZnOE}$, silicate or $\mathrm{ZnPh}$ cements for evaluation of their histological responses. 
Still, we are now confronted by the fact that initial in vitro tests are not completely reliable to define possible false-positive or falsenegative outcomes. For instance, if you challenge the in vitro research laboratories who adhere to their "own suggested" in vitro test \& ask if they routinely employ known toxic control agents e.g. glutaraldehyde in their system - they may respond that they don't concern themselves with controls-since such agents (glutaraldehyde, phenol, acetone) have long been grandfathered as pre-1948 accepted dental agents. If you ask those same in vitro researchers who sit on today's Pulp Biology committees to discuss \& define testing models \& challenge them with the critical issue of the biostability of the restorative interface \& the bacterial microleakage \& infection in their own in vitro system, they quickly respond they "are only required to follow the suggested BS EN ISO-10993-5 standards. It seems contradictory that some of the same individuals who may sit on various ISO committees, can also define standards. Isn't it ironic that some researchers can have it both ways?

\section{Does an ideal alternative in vitro biocompatibility tests exist?}

So far, we have reviewed what are important issues of biocompatibility testing. So let us present possible solutions to what we see as a testing conundrum. Initially, any pulp biology research group should demonstrate more than a proficient knowledge of enamel, dentine, pulp \& cementum tissues. More importantly, they must also recognize the dynamic biostability \& bacteriometic seal dimension of oral bacteria \& their toxins, which easily penetrate via microleakage from the tooth surface $\&$ through the restoration interface to the vital dentine \& pulp.

Today, a great deal of research is focused on the mechanical bond strength testing of new restorative agents when submitted for clinical use. Something to consider, Dr. Nakabayashi reported that the general breaking (cohesive) capacity of normal human dentine is approximately 21-megapascals (MPa) [90,91] On the other hand, the calculated modulus of enamel is up to $155 \mathrm{GPa} \&$ the thermal expansion is up to 2.3 X 10 [92]. In 1956, Craig \& Peyton demonstrated that enamel \& dentine have regional density extremes, which they demonstrated by Knoop indentation tests [93]. Ten Cate clearly demonstrated that enamel, dentine \& pulp tissues are variable substrates in their developmental, morphological, physiological \& aging phases-he stated that today's researchers should be responsible to be fully knowledgeable concerning all tooth substrates \& to demonstrate proficiency in the test model before they begin their research studies [94].

\section{Where might we focus new research issues?}

As one searches the web to identify in vivo \& in vitro studies of dental materials-it is clear that in vitro publications far exceed in vivo studies. We learned through our own decades of research experience-a well-defined \& meticulous ISO in vivo primate usage study takes several years of continuous effort-from inception to completion, as well as a strong funding base. In contrast, in vitro tests are less time consuming \& can be much less expensive to complete. As future ISO committees move towards harmonization of biocompatibility testing, they should consider to move beyond bond strength testing \& to explore the development of tests that merge the more important biological issue of the biostability of a long-term bacteriometic seal-from both a biological as well as a complete mechanically "sealed" interface.

\section{What is a bacteriometic seal?}

The term hermetic is from the blending of 2-ancient legends-the
Greek god Hermes \& the Egyptian god Thoth. Combined, they became personified as the mythological alchemist-Hermes-Trismegistus who allegedly possessed the magic ability to seal Pandora's treasure chest so no person or agent could gain entry to the contents without magical access. Perhaps Hermes was the first to understand the practical idea of "the seal is the deal". Century's later, in the Middle Ages \& Renaissance eras, alchemists realized that they needed an airtight seal to improve the efficiency of their alchemical apparatus to condense \& separate their novel mixtures into supposed magical potions. The 1939 JDR publication by Dr. Louis Grossman was first to use the term HERMETIC seal of dental restorations [95]. From that usage, Dr. John D. Ruby was first to think through \& apply the importance of a bacteriometic seal in his cariology lectures with students \& colleagues. Dr. Ruby's creation of the term bacteriometic seal brought together a unique meld of knowledge that stresses the importance of long-lasting biostability of a clinical seal against bacteria \& their biological penalties-to maintain enduring pulp vitality against microleakage [96].

\section{Is there a connection between microleakage \& biocom- patibility?}

Koch wrote that Marcellus of Rome was credited as the first person to remove caries from a human tooth with a scalpel $\&$ to fill the cavity with gum mastic \& ground pearl [97]. Pierre Fauchard (16781761) wrote that he \& his Paris colleagues would scoop debris out of cavities without any particular requirements \& then fill the space with thin gold foil mats, which they condensed with a mallet. Gold was the more popular \& successful filling agent than lead or tin foil-the latter 2-easily oxidized \& stained the tooth tissues black [98].

American dentists from the mid 1700's through the early 1900's used gold foil as a clinically popular restorative agent that was condensed into prepared cavities, however gold was barely affordable to individuals who couldn't afford the expense. On the other hand, amalgam was more economical \& the time devoted to its clinical placement was much less. The academics of the 1800's had no concept of material biocompatibility, however a few clinicians like Drs. G.V. Black (18361915) \& W.D. Miller (1853-1907) were beginning to understand that the flora of the oral cavity played a direct relationship to cause caries [99, 100]. Clinicians like Dr. M.H. Webb (1844-1883) were aware that the durability of the cavosurface seal along the interfacial margin was of primary importance for long-term clinical success [101]. Dr. Koch wrote, "the dental profession of the US may have been conceived of in the rural village of Greenfield Ohio, but its parturition took place in Maryland." [102]. Dr. Chapin A. Harris (1806-1860) from Greenfield, Ohio along with Horace Hayden were initial forces for several dental firsts. They organized the first university accredited dental school at Baltimore MD; they organized the first American Journal of Dental Science Journal \& they organized the first US Dental Society. Dr. Harris's 1855 US text Principles \& Practice of Dental Surgery was the first to provide clinical dentistry with scientific documentation as to what had previously been considered an art form-his chapters on cavity preparation \& filling materials are incredibly erudite for the young dental profession in the US of that era [103].

\section{The cavosurface margin: it leaks}

Koch's 1910 text was apparently the first to comment "by 1855 all of the amalgam restorations made in America through a long period of years were leaky" [104]. It had become apparent that many clinicians were observing failed amalgams, which from their introduction to the US, commercial amalgams had no formulation standards. By 
the mid 1800 's, due to the high cost of gold \& the time required for proper clinical gold foil placement, silver amalgam had become the most common restorative agent for the general population. Certain clinicians began to realize that amalgams had specific failure issuesthe most obvious were surface failure \& fracture along its cavosurface interface. In 1861, Sir John Tomes of England reported that 6 out of 7 silver-tin amalgam restorations had shrunk-but his one low-copper amalgam remained sealed [105]. In 1895, Dr. G.V. Black realized that companies needed to produce a standard amalgam formulation, which would provide long-term clinical stability \& prevent leakage along the restorative interface. Most pre-Black amalgam outcomes by the general clinicians demonstrated recurrent decay, pulp pathology \& necrosis, which generally resulted in extraction. Dr. Black's research demonstrated that a steady application of 25 -pounds pressure onto the amalgam surface caused it to flow \& after several months the amalgam slowly spread \& flattened without fracture or breaking from constant chewing pressure [106]. In 2005, Dr. J.W. Osborne validated Dr. Blacks 1895 amalgam flow data-demonstrating that creep was the apparent mechanism that self-sealed the more modern silver amalgams against microleagage- his data showed little to no corrosion products when placed in water or allowed to dry on the bench top [105].

In 1976, Dr. Kidd defined microleakage as the passage of bacteria, fluids, molecules or ions along the interface of a dental restoration \& the wall of the cavity preparation [106]. In 1983, Lin demonstrated that low-copper amalgam had a greater potential for corrosion-ultimately reducing microleakage along the restorative interface [107]. Since the 1940's, dental amalgam has been manufactured under rigid standards \& instructed to triturate \& insert under proper clinical manipulation. Dr. Miles Markley demonstrated that with proper mixing \& placement, amalgam restorations would last for many decades [108]. However, due to an almost phenomenological hyperbole regarding mercury toxicity $\&$ the rapid emergence of glass ionomers \& adhesive restorations since the 1970's, caused a decline in amalgam placement. Even more ironic, it seems incredible-in light of today's adhesive technologies-that some dental schools are not teaching Fusuyama's concepts of minimal intervention, cavity design \& restoration [109]. We think that G.V. Black would consider this as academic shortsightedness-failure to grasp the obvious.

Following Sir John Tomes observations on leaky cavosurface margins in the late 1800 "s, Dr. Ames of Chicago delivered a paper stating; "If hand amalgamation was complete and no free copper remained after mixing, dentine would not stain-more importantly, it was realized as a permanent antiseptic to prevent recurrent decay after placement of the definitive restoration" [110]. Several U.S dentists published their clinical observations, that certain filling materials were able to create a bacterial barrier to the underlying dentine \& vital pulp [111-115]. As we have discussed, Dr. Grossman was first to write "the necessity for having a hermetic seal during root canal treatment is obvious". The question remains-is there a difference between a physical-mechanical seal \& a bacterial-tight seal?

\section{The dynamic nature of microleakage}

In 1947, Dr. Bartlestone demonstrated that open enamel channels readily permitted microleakage of radiolabelled agents from the oral surface into the vital pulp \& vascular system within 15-minutes [116]. A few years later Dr. Nelson used various research methods (e.g. dyes, stains, bacteria, radioactive isotopes \& air pressure) to suggest that the restorative-enamel-dentine interface is an impermeable interface [117]. Research has shown that enamel has small lamella passageways that easily permit the seepage of oral fluids into the pulp. Drs. Going \& Massler reported that the extent of penetration depends on many factors e.g. molecular size, the cavity type, the seal of the restorative agent, the thermal environment between the cavity \& restorative agent \& the nature of the remaining smear debris layer after the tooth preparation is completed [118].

A 1939 study by Dr. Grossman evaluated the marginal seal of 10 -temporary filling restorative agents. One series of his tests used dyes, repeated over a maximum of 24-times. Of the 10-restorative agents, 6-showed definite dye microleakage \& 1-gave variable results. Another series of dye \& saliva tests showed 6-agents allowed no leakage, while 4-gave variable results. Dr. Grossman speculated that the large molecular size of salivary proteins prevented dye passage through the restoration interface. His $2^{\text {nd }}$ test series used Bacillus prodigious microörganisms to detect bacterial microleakage. Without exception, $\mathrm{ZnOE}$ was completely leak proof in all tests-much to Dr. Grossmans admitted surprise [119].

The issue of a bacteriometic seal against microleakage is now understood as a physical-mechanical barrier that forms a completely stable interfiffusion zone $-1^{\text {st }}$ reported in enamel by Dr. Gwinnett [120]. In 1982, Nakabayashi demonstrated a stable hybridized layer of adhesive that had penetrated into the etched intertubular dentine [121]. Studies by Drs. Brännström, Bergenholtz demonstrated that microleakage of bacteria are the prime cause of pulp inflammation, due to failure of the restorative agent to provide a bacteriometic seal along the entire restorative interface $[78,122]$. Their studies appear to explain the absence of bacteria in Dr. Grossman's 1938 study, which evaluated eugenol. Today studies have shown that eugenol is bactericidal \& so, it is excluded by the pre-grandfathered test-gate.

In 1987 Cox suggested that the real issues of dental material biocompatibility were divided between material toxicity (e.g. gluteraldehyde) versus the long-term biostability of the hybridized interface to exclude the invasion of bacterial via microleakage. We suggest you read the classic studies by Manley, Zander, Massler, Langeland, with particular notice of the erudite publication by Kakahashi. In vivo human studies by Brännström demonstrated that microleakage of bacterial factors through the restorative interface are the prime cause of pulp infection \& necrosis [81].

\section{Requisites for a Bacteriometic seal}

A series of clinical studies by Dr. Nyborg reported that restoration of cavities with various calcium hydroxide $\mathrm{Ca}(\mathrm{OH})_{2}$ agents was followed by a short period of pulp healing without any reported patient sensitivity. However, after several months placement, he observed pulp inflammation \& necrosis in substantial numbers of his clinical cases, showing stained bacteria in the empty $\mathrm{Ca}(\mathrm{OH})_{2}$, space-a consequence of microleakage. This is one of many clinical studies that cast doubt on the ability of $\mathrm{Ca}(\mathrm{OH})_{2}$ agents to sustain a stable bacteriometic seal against microleakage \& sustain long-term pulp vitality. Nyborg stated: "restorative procedures must be based upon long-term studies, supplemented by histo-pathological assessment" [123,124]. Dr. Barnes reported 1-year clinical observations from their university patient records, which noted the loss of human pulp vitality-due to the loss of the Dycal $^{\mathrm{sx}}$ base under amalgam restorations. They described the loss as "Disappearing Dycal ${ }^{\text {mo" }}$ - the consequence of microleakage along the unsealed restoration interface that simply permitted the Dycal ${ }^{\mathrm{m}}$ "pulp protection" agent to dissolve over the year of placement \& exit the restorative interface. As the Dycal ${ }^{\mathrm{mi}}$ base dissolved, opportunistic bacteria easily invaded along the restoration interface to recolonize 
\& form a cariogenic biofilm that resulted in recurrent caries \& pulp inflammation-in the absence of the Dycal "ix "pulp protection" [125].

As a result of the Nyborg \& Barnes articles, our pulp biology research group defined several in vivo studies. The $1^{\text {st }}$ study-published in 1982-was a 5-week vital pulp study in non-human primates. Following ISO guidelines, vital pulps were exposed at several intervals \& direct pulp capped with Dycal ${ }^{\text {Tw}}$. Evaluation of serial-sectioned microslides showed pulp healing, reorganization of soft tissue \& new dentine bridge formation directly adjacent to the $\mathrm{Dycal}^{\mathrm{m}}$ at the exposure site in 99 of 120-serial sectioned teeth [126].

The second study was a 1 \& 2-year proposal that combining histological \& microbiological data, that demonstrated $86 \%$ of the pulps had initially formed new dentine bridges in $67 \%$ of the exposed $\&$ direct Dycal ${ }^{\mathrm{m}}$ capped pulps. However, the dentine bridges showed tunnel defects through the entire bridge with stained Gram positive \& negative microörganisms \& recurring pulp inflammation that had invaded through the tunnels of the dentine bridges. Microbiological cultures of both aerobic \& anaerobic mocroörganisms from the empty space-previously occupied by the $\mathrm{CaOH}_{2}$ Dycal ${ }^{\mathrm{Ts}}$ base-below the amalgam was due to the failed bacteriometic seal of the amalgams [127].

As we have shown, we realize that in vitro tests are not refined enough to evaluate the same variables of an in vivo study. In the consideration of a bacteriometic seal, the research colleague must knowledgeable of the 3-mineralized tissues $\&$ the non-mineralized vital pulp tissue. In order to prevent failure of any dental restoration we need to create a long-term bacteriometic seal along the entire restoration interface \& its long-term ability to prevent bacteria \& their toxins to penetrate into the vital pulp, where they easily cause inflammation \& necrosis.

\section{Remaining challenges}

Where will the biological testing future proceed? We have endeavored to present all of the available literature to develop our biological testing timeline of restorative materials-the beginnings are traced from Dr. Kinyoun of the Marine hospital of Ellis Island of 1779. In vivo tests were first reported by Manley in 1936 [46] followed by an in vitro report of Kawahara in 1959 [37-39]. Since then, the scientific community has refined biological testing models to demonstrate that microleakage of microörganisms \& their products through the restorative interface are of greater damage to vital pulp tissues than the $\mathrm{pH}$ of restorative agents [75-82]. Improved in vitro tests have evolved to incorporate a dentine chamber that attempts to mimic the vital tooth, but lacks the complete physiological milieu of the vital dentine \& tooth substrates. It remains for future research colleagues to develop more sophisticated biological tests that are within realistic limits of reproducibility. As Dr. Charpy wrote "development, analysis of materials testing of any future agency should establish any new material as judged only by performance tests. . .give a meticulous and precise description of all tests; avoid all vagueness that permits or obliges any arbitrary decisions on the part of the personnel doing the testing; specify the relation between the precision of the testing and the precision required in the results of the tests; and state how the data are to be recorded" [16]. As Dr. Cotton stated "We must not be frozen into standard protocols, likewise our minds must not be frozen to old \& outdated ideas on testing adaptability \& change are paramount". As Dr. Ruby has noted "the bacteriometic seal is the deal" [96].

\section{Acknowledgements}

Each author owes a collective note of thanks to all of our academic
\& clinical colleagues who have assisted \& supported us in our formative research years \& later throughout our chosen academic careers.

\section{References}

1. Dalberg-Acton J (1895) Inaugural Lecture The Study of History Cambridge Univ.

2. Boyer C (1991) Euclid of Alexandria in: A History of Mathematics. John Wiley \& Sons Inc, USA.

3. Ketcham J (1901) The Life of Abraham Lincoln. AL Burt Inc: 435.

4. Snow J (1885) On the mode of communication of cholera. J Churchill, London, Eng.

5. Ross R (1897) Discovery that mosquitoes transmit malaria parasites. Report to the Indian Med Corps.

6. Kinyoun J (1887) Founder of The NIH \& The Hygienic Laboratory at Staten Island NY.

7. Hodgkin J (1997) Amalgam Read at The Southern Dent Assoc Mtg. Washington DC. Dent Cosmos S.S. White Dent Mngf Co 29.

8. Black G (1919) Method of making and testing dental amalgam alloys. Dent Cosmos 61: 735 .

9. Ruby J, Cox C, Akimoto N, Maeda N, Momoi Y (2010) The caries phenomenon: a timeline from witchcraft and superstitions to opinions of the 1500 s to today's science. Int $J$ Dent: 1-10.

10. Kuehns (1888) Dtsch, Mschr. Zahnaeilk: 446.

11. Eager J (1886) Denti di chiate teeth. Pub Health Rept: 16.

12. McKay FS (1916) Dental Cosmos 58: 479.

13. Truman H (1948) Legislation for the Nat Dent Res Act The $3^{\text {rd }}$ NIH agency.

14. Eisenhower D (1958) Signing of Legislation to Finance the Building of the NIDR facilities.

15. Dean H (1934) Classification of mottled enamel diagnosis. J Am Dent Assoc 42: 1421 1426.

16. Charpy G, Cornu-Thenard A (1917) Impact tests and the determination of resiliency in Metallurgical \& Chemical Engineering. eds Roeber \& Parmelee. Electrochemical Pub Co: 17.

17. US FDA 510(k) (1948) Class I \& Class II mats \& Devs Grandfather Clause for Biological Testing of Rest Mats.

18. In-vitro and in-vivo testing gates. Sampling, inspection (1978) Test Procedure Guide to Dent Mats \& Devs ( $8^{\text {th }}$ edn.): 203-210.

19. Von Leeuwenhock A (1700) A Letter to the Royal Society Philosophical Transactions of the Royal Society of London 63: 2 .

20. Souder W (1926) Physical properties of dental materials. Amalgam Dent Dig 32: 16.

21. Federation Dentaire International (1952) A voluntary nongovernmental group of international dental associations FDI Commission to Explore the creation of international testing standards.

22. Hunter W (1919) The role of sepsis and antisepsis in medicine McGill Univ.

23. Billings $F$ (1912) Chronic focal infection and their etiologic relations to arthritis and nephritis. Arch Int Med 4: 484.

24. Fish E, MacLean I (1936) The distribution of oral streptococci in tissues. Brit Dent $J$ 61: 336-362.

25. Gottlieb B, Orban B (1931) Die veranderungen der gewebe bei ubermassiger beanspruchung der zahne. Zahnarzil Instit der Weiner Univ.

26. Rickert U, Dixon C (131) The controlling of root surgery Procs $8^{\text {th }}$ Int Dent Cong. Paris IIIa: 15-22.

27. Grossman L (1941) Conservative treatment of pulpless teeth. J Am Dent Assoc 28: 1244-1251.

28. Inlge J (1955) The need for endodontic instrument standardization. Oral Surg 22: 12111214. [Crossref]

29. Hyakusoku H (1959) Effect of filling material on healing of periapical tissues. Odont Revy 6: 4-11.

30. Nicholls E (1962) Treatment of Traumatic Perfnorations of the Pulp Cavity. Oral Surg Oral Med Oral Path 15: 603-612. [Crossref] 
31. Rowe A (1965) A Report on the Use of a new material for Pulp Capping. Dent News: 6.

32. Torneck C (1966) Reaction of rat connective tissue to polyethylene tube implants: Part I. Oral Surg Oral Med Oral Path 21: 11-17. [Crossref]

33. Seltzer S, Bender I, Ziontz M (1963) The dynamics of pulp inflammation: correlation between actual histologic findings in the pulp. Oral Surg 16: 846-871. [Crossref]

34. Grossman L (1970) Endodontic Practice. $7^{\text {th }}$ edn.) Lea \& Febiger Philadelphia PA: 329 377.

35. Swerdlow H, Stanley H (1961) Response of the Human Dental Pulp to Amalgam Restorations. Oral Surg Oral Med Oral Path 15: 499-508.

36. Kawahara H, Tomli S (1959) Cellular Response to Ag-SN Amalgam. Jpn J Soc Prev Dent 2: 328-334.

37. Maizumi H, Sauerwein E (1962) Effect of various endodontic materials on cell cultures. Disch Zahn 17: 1628-1634.

38. Keresztesi K, Kellner G (1964) The biological effect of root filling materials. Scand J Dent Res 22: 333-341.

39. Leirskar J, Helgeland K (1972) A methodologic study of the effect of dental materials on growth and adhesion of animal cells in vitro. Scand J Dent Res 80: 120-133.

40. Spångberg L (1973) Kinetic and quantitative evaluation of material cytotoxicity invitro. Oral Surg 35: 389-401. [Crossref]

41. Manley E (1936) A preliminary investigation into the pulp response to various filling materials. Brit Dent J 50: 321-331.

42. Fletcher $\mathrm{T}$ (1873) The use of alcohol for drying a cavity: very shortly after the Godiva cement was introduced. Trans Odont Soc Grt Brit.

43. Schoenbeck F (1918) Verfahren zur herstellung von zahnkitt von glasiger porzellanahnlicher, schmelzartiger struktur. German Patent DE-306: 837.

44. Skinner K (1951) Silicate mixing \& finishing. Bull Nat Dent Assoc 10: Paragon Press.

45. ADA Council on Dental Materials (1984) Instruments and Equipment Reported Sensitivity to glass Ionomer luting cements. J Am Dent Assoc 109: 476.

46. Kidd E (1979) Microleakage: a review. J Dent 4: 199-206. [Crossref]

47. Manley E (1936) A preliminary investigation into the reaction of the pulp to various filling materials. J Brit Dent Assoc LX 70: 322-333.

48. Gurley W, Van Huysen G (1937) Histologic changes in teeth due to plastic filling materials. J Am Dent Assoc 24: 1806-1816.

49. Crowell W (1927) Physical chemistry of dental cements. J Am Dent Assoc 14: 10301048 .

50. Roydhouse R (1961) Silicate cements and pulpal degeneration. J Am Dent Assoc 62: 258-263.

51. Brännström M, Nyborg H (1971) The presence of bacteria in cavities filled with silicate cement and composite resin materials. Swed Dent J 64: 149-155. [Crossref]

52. International Organization for Standard ISO-10993, (2014) Biological Evaluation of Medical Devices Part 1: Evaluation \& Testing. Replacing ${ }^{\#}$ G87-1 ${ }^{\#} 8294$.

53. Torneck C (1977) Discussion of polymorphonuclear bacterial interaction as a pathogenic mechanism in periodontal disease. J Endod 3: 301-303.

54. Bergman B, Hugoson A, Olsson C (1977) Caries and periodontal status in patients fitted with removable partial dentures. J Clin Periodont 4: 134-146. [Crossref]

55. Souder W, Peters C (1920) An investigation of the physical properties of dental materials. Dent Cosmos. 62: 305-335.

56. Fish E (1932) The pathology of the dentine and the dental pulp. Brit Dent J 53: 351363.

57. Barker J (1942) Reactions of the pulp to various filling materials and clinical procedures. Aust J Dent 46: 226-232.

58. Zander H, Pejko I (1947) Protection of pulp under silicate cements with cavity varnishes and cements. J Am Dent Assoc 34: 811-819. [Crossref]

59. Seelig A, Lefkowitz W (1950) Pulp response to filling materials. NY Dent J 16: 540. [Crossref]

60. Berk H (1950) The effect of calcium hydroxide-methyl cellulose paste on dental pulp. J Dent Child 17: 65-68.

61. Massler M (1968) Biologic considerations in the selection and use of restorative materials. J Dent Assoc Sud AF 23: 56-69. [Crossref]

62. Pappas A, Massler M (1959) Bioassay of cavity liners under silicate cement fillings in rat incisors. J Dent Child 26: 335-342.

63. Mitchell D (1959) The irritational qualities of dental materials. J Am Dent Assoc 59: 954-966. [Crossref]

64. Brännström M, Nyborg H (1971) Pulpal protection by a cavity liner applied as a thin film beneath deep silicate restorations. J Dent Res 50: 90-95. [Crossref]

65. Paffenbarger GC (1978) Guide to Dental Material and Devices ( $8^{\text {th }}$ edn.) $J$ Am Dent Assoc. [Crossref]

66. FDI Standards (1958) Establishing ISØ/TC106 Dentistry of six working groups.

67. ISO (1997) International Organization for Standardization Tech Rept \#11405 Dental materials guidance on testing adhesion to tooth substrates.

68. Cotton WR (1978) Pulp Biology Group Symposium, IADR Meeting Copenhagen.

69. Guide to Dental Materials and Devices (1976) Chap 16. Recommended Standard Practices for Biological and Clinical Evaluations: 200-215.

70. Cotton W (1975) Pulp Biology Group Chapter Awards Joint Proceedings of the Annual Session of the Am Assoc Dent Res \& Int Assoc Dent Res, USA

71. Spångberg L (1969) Biological effects of root canal filling materials. Odont Revy 20: 289-299.

72. Autian J (1970) The use of rabbit implants and tissue culture tests for the evaluation of dental materials. J Oral Rehab 4: 275-290. [Crossref]

73. Tronstad L, Wennberg A (1980) In vitro assessment of the toxicity of filling materials. Int Endod J 13: 131-138. [Crossref]

74. International Organization for Standardization (2009) Test gate Guidelines 4049 Dentistry-Polymer-based restorative materials.

75. Brännström M (1984) Communication between the oral cavity and the dental pulp associated with restorative treatment. Oper Dent 9: 57-68. [Crossref]

76. Kakahashi S, Stanley H, Fitzgerald R (1965) The effects of surgical exposures of denta pulps in germ-free and conventional laboratory rats. Oral Surg Oral Med Oral Path 20: 340-349. [Crossref]

77. Brännström M, Nyborg H (1973) Cavity treatment with a microbicidal fluoride solution: growth of bacteria and effect of the pulp. J Prost Dent 30: 303-310. [Crossref]

78. Bergenholtz G (1977) Effect of bacterial products on inflammatory reactions in the dental pulp. Scand J Dent Res 85: 122-129. [Crossref]

79. Bergenholtz G, Cox C, Loesche W, Sayed S (1982) Bacterial leakage around dental restorations: its effect on the dental pulp. J Oral Path Med 1: 439-450. [Crossref]

80. Cox C, Bergenholtz G, Baker J (1983) A 14-day observation of wound healing of exposed/ contaminated monkey pulps. J Dent Res 62: 663.

81. Cox C, Keall C, Keall H, Ostro E, Bergenholtz G (1987) Biocompatibility of surfacesealed dental materials against exposed pulps. J Prosth Dent 57: 1-8. [Crossref]

82. Cox C, Suzuki S (1994) Re-evaluating pulp protection: calcium hydroxide liners vs cohesive hybridization. J Am Dent Assoc 125: 823-831. [Crossref]

83. Van Hassell H (1971) Physiology of the human dental pulp. Oral Surg Oral Med Oral Path 32: 126-134. [Crossref]

84. Autian J (1975) Structure toxicity relationships of acrylic monomers. Envir Health Persp 6: 141-152. [Crossref]

85. O'Brien W, Johnson W, Heinkel D (1977) Surface properties of dental amalgam roughness produced by setting reaction. J Am Dent Assoc 94: 891-694. [Crossref]

86. Sládek N (2003) Human aldehyde dehydrogenase: potential pathology, pharmacological, and toxicological impact. J Biochem Molec Toxic 17: 7-17. [Crossref]

87. Spagnuolo G, D'Anto V, Cosentino C, Schweiki H, Rengo S (2006) Effect of n-acetyl1-cystine on ros production and cell death caused by HEMA in human primary gingival fibroblasts. Biomats 27: 1803-1809. [Crossref]

88. FDA Report (2010) California \& 12-other states, canada, the european union and china have officially banned BPA from childrens' products. USA Today.

89. Lucas L, Lemons J (1991) Biodegradation of restorative metallic system. Effects and Side-effects of Dental Restorative Materials. NIDR Symposium: 32-37.

90. Sano L, Krueger A, Landrum P (2005) Chronic toxicity of glutaraldehyde: differential 
sensitivity of three freshwater organisms. Aqua Toxic 71: 283-296. [Crossref]

91. Nakabayashi N, Saimi Y (1996) Bonding to intact dentin. J Dent Res: 1706-1715. [Crossref]

92. Raue L, Klein H (2011) Calculation of anisotropic properties of dental enamel from synchrotron data. J Sync Rad 18: 1107. [Crossref]

93. Craig R, Peyton F (1958) The microhardness of enamel, and dentin. J Dent Res 37: 661-668.

94. Ten Cate A (2002) Oral Histology, Development, Structure and Function (5 $5^{\text {th }}$ edn.) Mosby-Year Book, Toronto, Ontario CA.

95. Grossman L (1939) A study of temporary fillings as hermetic sealing agents. J Dent Res 18: 67-71.

96. Ruby J (1999) Pediatric Dentistry Postgraduate Lecture Series. University of Alabama School of Dentistry.

97. Koch C (1910) Etruscan and roman antiquities Hist Dent Sci 1: 8-11.

98. Fauchard P (1746) Methods for removing decay and restoring teeth. Le chirurgien dentist ou traite des dents.

99. Black G (1884) The Formation of Poisons by Microorganisms: A Biological Study of the Germ Theory of Disease Blackiston's \& Son Philadelphia, PA, USA.

100. Miller W (1891) The human mouth as a focus of infection. Lancet 138: 340.

101. Webb M (1883) Notes on Operative Dentistry The S.S. White Dental Manufacturing, Philadelphia, PA, USA.

102. Koch C (1910) A History of Dental Surgery. Fort Wayne Indiana 1: 75.

103. Harris C (1885) Harris's Principles \& Practice of Dental Surgery Lindsay \& Blakiston Philadelphia, PA. USA, $6^{\text {th }}$ ed.

104. Koch C (1910) History of Dental Surgery: History of the development of Dentistry Plastic Fillings Leaky Amalgams. Nat Art Pub co: 174-192.

105. Tomes J (1861) Leaky amalgam fillings Transactions of the Odont Soc Great Britain: 111.

106. Black G (1895) An investigation of the physical characters of the human teeth in relation to their diseases and to practical dental operations, together with the physical characters of the filling material. Dent Cosmos 37: 353-36.

107. Osborn J (2006) Creep as a mechanism for sealing amalgam. Oper Dent 31: 161-164.

108. Kidd E (1976) Microleakage: a review J Dent 4: 199.

109. Lin J, Marshall G, Marshall S (1983) Microstructures of cu-rich amalgams after corrosion. J Dent Res 62: 112-115.
110. Markley M (1951) Restorations of silver amalgam. J Am Dent Assoc 43: 133-141.

111. Fusayama T (1993) A simple pain free adhesive system by minimal reduction and total etching. A New System of Cavity Preparation Ishiyaku EuroAmerica Inc. Tokyo, St. Louis.

112. Ames W (1892) A new oxyphosphate for crown setting. Dent Cosmos 34: 392-395.

113. Webster A (1903) The value of amalgams, cements, and gutta-percha as barriers against bacteria. West Dent JX: XVII.

114. Volland A (1904) Filling materials as barriers to bacteria Dent Sum XXIV: 9.

115. Frasher C (1929) A study of the efficiency of dental fillings. J Dent Res 9: 507-517.

116. Bartlestone HJ (1950) Radioiodine penetration through intact enamel, with uptake by bloodstream and thyroid gland . J Dent Res 30: 728-733. [Crossref]

117. Nelson R, Wolcott R, Paffenbarger G (1952) Fluid exchange at the margins of dental restorations. J Am Dent Assoc 44: 288-295. [Crossref]

118. Going R, Massler M, Dute H (1960) Marginal penetration of dental restorations as studied by cresyl violet dye and I-131. J Am Den Assoc 61: 285-300.

119. Grossman L (1939) A fluorescent dye method for demonstrating leakage around dental restorations. J Dent Res 45: 1485-1492. [Crossref]

120. Gwinnett A, Matsui K (1967) A study of enamel adhesives: the physical relationship between enamel and adhesive. Arch Oral Biol 12: 1615-1620. [Crossref]

121. Nakabayashi N, Katsunori N, Masuhara E (1982) The promotion of adhesion by the infiltration of monomers into tooth substrates. J Biomed Mat Res 16: 265-273. [Crossref]

122. Brännström M (1982) Dentin and Pulp in Restorative Dentistry ( $2^{\text {nd }}$ edn.) Wolfe Medical Pub, London, UK.

123. Nyborg H (1955) Healing process in the pulp on capping: a morphologic study. experiment on surgical lesions of the pulp in dog and man. Acta Odont Scand: 13.[Crossref]

124. Nyborg H (1958) Healing processes in the pulp on capping: a morphologic study. Acta Odont: 605-612. [Crossref]

125. Barnes I, Kidd E (1979) Disappearing dycal. Brit Dent J 147: 111. [Crossref]

126. Cox C, Bergenholtz G, Fitzgerald M, Heys D, Heys R (1982) Capping of the denta pulp mechanically exposed to the oral microflora - a 5 week observation of wound healing in the monkey. J Oral Path: 327-339. [Crossref]

127. Cox C, Bergenholtz G, Syed S, Heys D, Fitzgerald M, et al (1985) Pulp capping of the dental pulp mechanically exposed to oral microflora: a 1-2 year observation of wound healing in the monkey. J Oral Path 14: 156-168. [Crossref

Copyright: (C2016 Cox CF. This is an open-access article distributed under the terms of the Creative Commons Attribution License, which permits unrestricted use, distribution, and reproduction in any medium, provided the original author and source are credited. 